\title{
The Community Rights of the Natural Resources and Community Forests Management and Utilization
}

\author{
Boonmee Totum, Faculty of Humanity and Social Science, Ubon Ratchathani Rajabhat University, Thailand \\ sakhonlatee@hotmail.com \\ *Sanya Kenaphoom, Faculty of Political Science and Public Administration, Rajabhat Mahasarakham \\ University, Thailand, zumsa_17@hotmail.com \\ *Corresponding Author
}

\begin{abstract}
Community forest is one of the most important natural resource bases, especially as the source of food resources to communities from the past to the present. Therefore, the forest area should be managed through a process of participation from people and community organizations for the benefit that is consistent with the way of life of all people in the community, both on their livelihoods, Kinship family system, traditions, beliefs, powers and regulations in the community. Community forests are managed in a variety of ways depending on the geospatial and cultural traditions of the local community. This research aimed to analyze the problem of community rights in the management and utilization of natural resources and forests, and to study guidelines for the development of community rights in the management and utilization of natural resources and community forests. This research studied was hold at Ban Dong Yang community, Koeh sub-district, Khueng Nai district, Ubon Ratchathani Province, Thailand. Operating by In-depth interviews with 12 key contributors and 10 participants in small group discussions, using a randomized method. The data was analyzed by using content analysis and writing a descriptive narrative. The research results were found that; 1. Management problems include unstructured work, community participation, lack of support from outside agencies, lack of long-term management practices and development plans, and lack of public relations to build knowledge and understanding of community forest areas. However, there were Use rights issue; Abuse of community rights from non-residents, disrespect for community rights in agriculture, illegal logging in forests, lack of agreement and clear timelines on the right to use community forest resources, community lack of knowledge and understanding in extending the right to use natural resources.

2. Guidelines for the development of community rights in the management and utilization of natural resources and community forests found that (1) the factors of cooperation and strength within the community are community leaders, community forestry committees, community / civil society, children and youth networks, religious institutions, educational institutions. (2) The factors of support and promotion from outside the community are government agencies, local administrative bodies / forest resources management bureaus, private sector / associations / foundations, organization groups and community forest network partners. (3) the conditional factors for success are forest value awareness, community attitudes, community involvement, forest knowledge, sacrifice / volunteering and unity.
\end{abstract}

Keywords: Problems, Community Rights, Management, Natural Resources and Forests

Received: 09.12.2020 $\quad$ Accepted: 13.01.2021 $\quad$ Published: 02.02.2021

\section{Introduction}

At present, natural resource and environmental management focuses on the public and community sectors to participate with the state in management, as well as developing policies to guide the management, including legal mechanisms to support management rights in accordance with trends and developments in natural resource management by the local communities are subject to the roles and obligations of traditional community organizations, and community agreements are the key mechanisms by which communities manage their natural resources in the area. If natural resources and environment are viewed as fundamental factors for the life of a local community, the community has the ability to monitor their own livelihoods which are the right to life and the means of living. In such a case, if it is deemed that natural resources in a particular community exist for the livelihood of the peoples or local communities, such local people or communities shall have the right over that resource to conserve and manage them for Natural resources are maintained for sustainable using (Udomsak Sinthipong 2015: 104-113). 
The Constitution of the Kingdom of Thailand 2017, Article 43 provides that individuals and communities have the right to manage, maintain and utilize balanced and sustainable natural resources, environment and biodiversity in a manner prescribed by law as well as being able to use the right to recommend to government agencies on actions that will affect the peaceful livelihood of people or communities. The provision is a natural resource management measure that is not only provided by the state or the private sector in the management, maintenance or utilization of natural resources and the environment, but it is a principle that recognizes the importance of natural resources that Non-state-owned resources solely or granting private sector rights solely to manage, maintain, or utilize natural resources. but it is the giving of natural resources a common resource by the community as close to it and being a direct stakeholder in the community's resources, which is considered to be the holder of the community right to manage, co-maintain and make use of natural resources and environment in order to achieve a balance and sustainability in the management of natural resources and the environment. In addition, Article 57 provides the state with a constitutional duty that "The State must conserve, protect, maintain, restore, manage and use or provide for a balanced and sustainable utilization of natural resources, environment and biodiversity. In this regard, the relevant local people and communities must also participate in and benefit from such undertaking as provided by law." It was adhering to the participation of people and local communities as well as determines the duties of various people in the preservation of natural resources and the environment, including Traditional local communities, local government organizations, environmental NGOs and the general public. The right of the community to the management of natural resources and the environment, the right to engage with states in the management, stewardship and maintenance of local natural resources and the environment, and the right to make balanced and sustainable use of local natural resources and the environment (Orrathai Intachaiwong. 2017: 171-193). As the same applies to the Community Forests Act. 2019 , it is intention to encourage communities to join with the state in the efficient management of natural resources in community forests which will result in the integrity and sustainability of the natural resources, environment and biodiversity of the country.

Community forest therefore is a forest area that the community has operated or is permitted by law to operate in conjunction with the competent authorities to continuously manage forest activities under relevant rules, regulations, procedures and programs which may also be consistent with the local beliefs and culture of the community, and the management or operation thereof is for the conservation and sustainable use of the community. The community forest is considered one of the important natural resource bases, especially as the source of food resources to the local community from past to present. Therefore, forest areas that are managed through a process of participation from people and community organizations, directly and indirectly, in accordance with local beliefs and cultures, for the benefit of continuous community needs, are forests that people use in accordance with way of life of all people in that community, including livelihoods, kinship family systems, beliefs, power and regulations in the community. Therefore, community forests are managed in a variety of ways depending on the ecological and cultural characteristics of the local community. Community forest of Ban Dong Yang Tam Kao, Khueng Nai District Ubon Ratchathani Province occupies an area of 839 Rai, is a community forest in the area of responsibility of the Ban Dong Yang Community Forest Committee in Moo 8 and Moo 12, it is an abundant forest with various types of wood such as gurjan, Burma Sal, Ingyin etc., it is a sandy loamy soil, having an area adjacent to Lamsebok river serves to moisturize the forest and the ground. The community forest is considered a common property of the community where all members of the community have equal rights in the management and use of the forest as a food source, herbal medicine, and a large community mall. But at the same time, there are problems from members of other communities hijacking resources, problems from members of the community not cooperating in the maintenance of community forests by illegal logging in forests, etc. (Ubon Provincial Statistical Office, 2019). The problems from laws that give communities the power to manage and utilize to a limited extent to the inability to have absolute power, absolute management and administrative issues in the form of community forestry committees, as well as support from government agencies as well.

Therefore, based on this issue and its importance, the researcher is interested in studying the issue of community rights in the management and utilization of natural resources and forests. This study is part of the subject research "Community rights to manage and utilize community natural and forest resources in community forest areas of Ban Dong Yang, Koee Sub-district, Ubon Ratchathani Province". This will lead to building cooperation with communities in resolving the issue of community rights in managing and utilizing the natural resources and forests of the communities in the area. 


\section{Research objectives}

1. To analyze problems related to the principles of community rights in the management and utilization of natural resources and forests.

2. To present guidelines for the development of community rights in the management and utilization of natural resources and community forests.

\section{Research methodology}

This research is a qualitative research with the following methods of research.

Research Area: This research is a qualitative research focused on the problem of community rights management and utilization of natural resources and forests in the Ban Dong Yang community forest area, Koh Ee Sub-district, Ubon Ratchathani Province.

Times of research: This study was one year or 12 months between 2018-2019.

Population and sample: The sample group in this research were 13 users and stakeholders in the management of natural resources and forests in the area of Ban Dong Yang Community, Koh Ee Sub-district, Ubon Ratchathani Province, as follows: 2 community leaders, 2 villagers, 3 community forestry committees, 2 villagers, 2 forestry scholars, 1 local government leader, and 1 religious leader monk which the purposive Samplings.

Research instruments: These include (1) interview form on the problem of community rights in the management and utilization of community natural resources and forests. (2) Cooperative and NonParticipatory Observations on Community Rights to the Management and Use of Community Forest, as well as performing community rituals and behaviors or groups of participants in various activities related to community forest management.

Data analysis: the data from document and key-informant interviewing were analyzed by the content analysis with process as follows: (1) word grouping, (2) explanation, (3) interpretation, (4) description, the composition of the words by organizing the pre- and post-analysis of the content of the analysis, along with the descriptions of each content and event interrelated.

\section{Research results}

The researcher summarizes the research results into issues of management rights and community forest utilization as follows:

\section{Management rights issues \\ Working problems that do not have a formal system: The Community Forestry Committee has not yet clearly planned work on such matters: setting the length of time for monthly or bi-monthly meetings, setting up common utilization regulations, etc. However, the Community Forestry Committees will meet only when government agencies or forestry officials join in with village's activity. From inquiries from community leaders said “.... Once in a while, there will be a community forest committee meeting, because the committee members are village people or on the occasion of the reforestation activities where forestry officials seek cooperation, there will be an opportunity to meet and discuss on an individual issue, some phone calls. therefore, I do not frequently invite meetings..." (Wasana Bunprakarn, interview: 2019). In addition, it was found that the management problems in the form of the community forest committee were The division of duties and responsibilities of each party, along with unclear regulations until many people did not understand their rights and duties, some of the community forestry committees are very old, some rarely have time to perform with their changing work and duties, their responsibilities are shared with some committee members and primarily with the community forest chair or headman.}

Problem of community's participation: Some villagers did not pay attention or participate in forest conservation and restoration campaigns according to their rights and obligations, because they saw that it was already the responsibility of the Community Forestry Committee, and moreover, it is attached to the mission of agriculture, which spends most of the time in farming, so there is no time to join community forest activities. From interviewing with representatives of villagers in Moo 8, it was found that “...There was an announcement from the amplifier from the home village headman to help plant forests, build roads to block forest fires, but did not attend because there was work to do at fields and have to take care of the grandchildren...." (Pisamai Kongsri, interview: 2019) The community forest is also the responsibility of Village No. 8 and Village No. 12, where both groups of villagers have rights to management and mutual 
benefit. However, the important government documents stating that only Dong Yang Village, Moo 12, participates in community forest development together with government agencies according to the law This is why many villagers in Village 8 claim that the forest belongs to Village 12, thus lacking the motivation to enter the forest management rights together with Village No.12. In addition, there were problems with the lack of participation or cooperation from the young generation, which were children and youth, lack of connection and inducement to awareness of the importance and joint activities with the community forest committee. It can be seen that most of the time forest management is under the care of the elderly, so the transition from parents, grandfather, grandmother, aunt, uncle to descendants to inherit will has not yet happened.

Problems lacking support from outside agencies: Community forests are primarily self-reliant, when there are problems or barriers to solving them within the community, it can be seen that there is few support or assistance from outside agencies. Although communities can be self-sufficient to some extent, their potential is limited, making the villagers' community forest management ineffective and effective such as knowledge and understanding of conservation, restoration, maintenance is based on folk wisdom, the cultivation of certain species of trees to grow and expand the plants by themselves, the forest fire barriers are based on existing knowledge and materials, etc. However, the community still needs attention from government agencies to help co-ordinate the community with relevant agencies such as the collaboration in obtaining knowledge support from the Forest Service, a study visiting in a strengthened community forest area, as well as a budget for community forest management, etc.

Lack of management approaches and long-term development plans: The community forest committee and villagers who are members of the community forest continue to act in the conservation, restoration, and preservation of forests according to the traditional local wisdom that The immediate problem does not have a plan for the movement for the restoration of community forest areas to be a public resource for the community, according to the concept of a community that has the right to protect, care and use together such as the long-term plans for the future of the group to represent villagers in community forest management, the 3 or 5 year forest conservation and restoration plan, the future plans for organizing an up-to-date database of trees, wildlife, plant species, etc.., the improvement of the community forest database system that matches the reality is clear in the distance to the community forest boundary to prevent forest encroachment, the budget plan that outlines the costs needed to manage the forest such as fire-proofing, road-going routes to facilitate forest intrusion surveillance and forest fire prevention, consumption expenses for forest activities, etc. including the Consciousness Building Plan for the Community to Love and Cherish the Forest Sustainable. While most of the people around the community forest do some cooperation in conserving the forest and its intra-forest resources, some others may not yet be fully aware of forest conservation which can lead to neglect in the care of forests in the future if the community forest development strategy is not planned to address any problems that may arise in the future.

Lack of public relations to build knowledge and understanding about community forest areas: The community forest is an interesting area of forest combined with a way of life and living culture. The community has several charming attractions, as evidenced by the village motto: "Large forest communities, ancient Thai land, carry on traditions, famous good torch, Outstanding culture, exceptionally beautiful large rubber trees, a lot of wood species, together to help developing" The dominant feature in the village motto, mostly from the Ban Dong Yang community forest, even called " Large forest community", famous good torch which if talking about a torch that ignites the tinder from Yang tree, a good torch of quality must be the torch of Ban Dong Yang only because it is a product derived from the oil of the Yang tree that are born in the village and in the community forest. In addition, the community forest has a wide variety of plants, cereals and wildlife that can be both a food source and an eco-tourism destination because Ban Dong Yang Community is a unique natural source and a cultural source related to Ecosystem and is a suitable area for the development of Ban Dong Yang Community Forest to be an eco-tourism destination. “...Ban Dong Yang is good in many ways.... has forest resources.... has good social capital, but a lack of public relations at large, most will be known within or nearby communities, so Ban Dong Yang has the potential that will definitely develop..." (Pitipong Yingpatsaranan, interview: 2019) However, due to the management of such community forest areas, there is a lack of knowledge for developing an eco-tourism destination and a lack of public relations in online society to be widely perceived by outside society. This may be because the majority of community 
forest board caregivers are old people and may not be as proficient in technology, which is one of the problems and obstacles in the public relations of social capital to be well known.

\section{The right to use the Community forest}

Problems of violation of community rights from people from different areas: Because the Ban Dong Yang Community Forest is an area rich in natural resources with many different types of forest such as Mushrooms, bamboo shoots, red ant eggs, oil from Yang tree etc., Causing other local communities nearby or from far away to vie for resources Such as mushroom picking season, red ant egg collection, etc. Often it appears villagers from other villages come to find mushrooms, bring them to eat and sell some during the day and night, sometimes there are also chartered cars. "...Other villages, he didn't have a community forest, didn't have a mushroom forest like Baan Dong Yang, so he came in to find mushrooms or search for forest items in the forest of Ban Dong Yang..." (Rueng Bunjong, interview: 2019). The nature of these problems causes degradation of natural resources and forests, affecting rights to conservation, restoration, management, maintenance and utilization and can lead to conflicts between communities.

Problem of disrespect for community rights in occupation: Some villagers do not yet fully understand the community right to use community forests, which are mutually exclusive forests, not belonging to anyone to occupy or use solely. Ban Dong Yang community forest area of 839 rai, adjacent to farms and gardens, which is an area of farming for villagers, therefore, the boundary is determined by using the forest line as a basis, without any gated boundary, so the problem is the encroachment of the community forest's land area by means of clearing methods or Plow land for farming, slightly surpassing the forest boundary. However, sometimes it is more time for a community leader or community forest director to be notified by the villagers who witness or make a complaint and, until then, a warning to provide clear boundaries with the intruders, it has greatly damaged the community forest area as well as the trees and plants, causing the need to restore and replant the damaged parts of the forest which is the use of individual rights without respect of community rights.

The problem of illegal logging in forests: Since the Ban Dong Yang community forest has many valuable perennials such as Yangna, Teak, Siamese Rosewood, Burmese Sal, Siamensis etc... Especially the Siamese Rosewood is the expensive wood which is often the cause of illegal cuts. According to the community leader, Village Headman 12 said "...There is a smuggling of Siamese Rosewood in the forest on a regular basis because there are a lot of rosewood in the forest, villagers living next to the forest, hearing the sound of falling trees at night, will come to notify the village headman. Then, an assistant village headman, villagers and community forest committees will be called to help out the illegal logging group...." (Wasana Bunprakarn, interview: 2019). It can be seen that most of them are foreigners who come to smuggle wood, which is considered a violation of the rights of the community who conserve, restore, maintain the community forest to be used together in the community.

Lack of clear terms, agreements and timelines on the right to use community forest resources: There is no agreement on the number or quantity per person entering the forest on the use of natural resources from community forests, it is also the freedom to use the natural resources collected from community forests such as Some people find enough to eat each meal in the family, but others either to eat and to sell or to sell only. It can be seen that the needs of individuals are not sufficiently available, which may prevent the natural resources available in the community forest to be able to grow up to their needs such searching for mushrooms that collected all the small and large flowers, sometimes taking them whole fungi for breeding was seen, or finding and digging up un-landfill taro, young vines, etc. These natural resources can lead to extinction, and no precise time or season has yet been established for forest conservation or restoration, allowing forests to recover from harvest and use by villagers. Consequently, such characteristics can result in forest degradation and future resource scarcity or competition if the community lacks awareness of the economical and cost-effective use of community forest resources.

The community lacks knowledge and understanding in extending the right to utilize community forest resources: Villagers are known to use different forms of community forest, for example: finding forest objects, picking firewood, finding mushrooms, bamboo shoots, red ant eggs, forest fruits, etc. in order to be meal of family and commercial trade, which there is a community market every evening at Ban Dong Yang, 
but the community does not understand the sustainable use of forests that lack of extension and added value to community forest products such as planting and expanding the cultivation of vegetables and food from the wild for themselves in their own farmland, thereby reducing dependence on community forests, giving the forests an opportunity to recuperate. Lack of processing, because processing will allow villagers to have food from the forest all year round and can be sold as well. Marketing or trade association to negotiate with middlemen which the wild food sold by villagers in the local community market, merchants from other areas will pick up and sell them at a higher price than the price they buy from the villagers, causing the villagers to lose their profits. While the forest products the villagers sell are raw materials, natural products without any chemical contamination, can be consumed and consumed with peace of mind. Consequently, if the community understands the principle of extending their right to take advantage of the forest to the full value it has, the villagers will be able to live in a sustainable and happy way.

Guidelines for the development of community rights in the management and utilization of natural resources and community forestry, can be divided into 3 factors:

3.1 The internal Factors; cooperation and strength of individuals, organizations and network partners within the community include; (1) Community leaders must have good knowledge, competence in activities that exist in the community, including virtue such as generosity, acceptance in the community, commitment to work and the ability to coordinate, and can negotiate various matters, relatively stable, good relationships, having power or social influence able to influence people in their community. (2) Community Forests Committee must cooperate with the competent official in arranging zoning, signs or other marks, issuing regulations on community forest management, establish guidelines for community forest recruitment and centralized property management of community forest, maintenance of community forest, community forest maintenance and restoration, promote education, learn and raise awareness about conservation and restoration of natural resources, environment and biodiversity in community forests, mediate or compromise in the event of a conflict in community forest management and take appropriate action to prevent or mitigate damage to community forests. (3) Community and civil society as the gathering of community forest management committees or community forestry members with a common goal to learn and build understanding, exchange experiences to lead to sustainable community forest management. (4) Children and Youth Network as network of young people who will be an important force in the conservation and restoration of community forests by providing opportunities for children and young people to learn and understand the true value and benefits of forests until they become conscious of the community forest which is home their own birth, they love and cherish, do not want others to destroy and carry out the will from generation to generation. (5) Religious institute, the integration of religious doctrines in forest conservation management so that people and forests coexist in nature, build relationships between nature and people in the community to create support for one another by not hiding one another, having compassion for nature, realize the value of the forest in the area and help to take care of it by participating in joint activities such as forest ordination, sanctuary setting. And (6) Educational institution, source of incubation and transfer of knowledge, wisdom to children and youth who come to study in educational institutions as well as knowledge that is academic principles in managing and utilizing the community forest. Learning from real learning sources can enable children and youth to be better absorbed with nature by making community forests a diverse natural learning center, being an ecotourism destination for the community where educational institutions are responsible for instilling knowledge, wisdom and guiding local communities to sustainable development.

The external factors, the support and promotion of public and private organizations include (1) Government agencies / local government organizations / Office of forest resources management, Responsible to support, promote consideration of community forest establishment requests, expand community forest areas or withdraw community forests, approve community forest management plans, give approval to supervise, remove community forest management committees, appoint and remove community forest officers, community forest regulations, following up and evaluating the community forest management results of the community forest management committee by giving advice and consulting to the community forest management committee on the management of community forests, including supporting and promoting the budget, activities, plants and plants for joint afforestation activities, conservation and forest rehabilitation with communities, etc. (2) Private Sector/ Association/ Foundation This is to create cooperation and support the operation of community forests, through a model of participation activities such 
as community natural resource conservation activities, reforestation activities, natural resource management activities, building networks to conserve community forest natural resources, etc. (3) Community forest network organizations and partners, an activity in the form of integrating community forest management together with the community forest network partners, which may be in the form of a study trip for the model community forest or governance community forest to improve and develop its own local community forest in exchange for mutual learning and doing joint activities at appropriate opportunities

key-Success factors for Management and Use of Community Forests include (1) Awareness of community forest values, in particular, people in the community must realize the value and benefits of the forest that the community should receive and the benefit that the forest has to the community, being food, habitat, and medicine for people in the community and animals, recreation and a natural learning center for people in the community and other interested people. When the community and society recognize this value, it can be the basis for sustainable community forest management. (2) Positive attitude of the community, the concept of community forest in which the community must understand that it does not necessarily have ownership of the forest area, but has the right to manage it, use it together which It is not just about planting trees or promoting forest conditions, but on people and the relationship between people and communities and the environment concerning the rural and community forest development and community action for the benefit of the community in which people and trees coexist, in which the community places the right attitude towards community forests. (3) The participation of the community, Management is organized from participation in decision-making, discussing community forest issues, attending meetings to solve problems and making decisions and proposing solutions or solutions for community forest problems, participate in review of community forest rules, participate in community forest surveys, join forest planting, participate in forest training, participate in review of community forest boundaries, contact with various government agencies and participate in forest rituals, participation benefits: of wood construction or repair of houses, wood-fired firewood, collecting mushrooms or asparagus or other vegetables, as well as other plants. Collect medicinal plants and use water in community forests for consumption and agriculture. And Participation in the assessment: Co-monitor and control the implementation of community forest conservation activities, jointly assess forest utilization, and assess related problems and obstacles. (4) Knowledge about the forest, The indispensable thing that the community must have is the knowledge of the forest, which may be knowledge of local wisdom or community culture, as well as modern knowledge in the management, conservation, restoration and use of shared community forests together such as knowledge of plant conservation, propagation, planting, maintenance as well as forest protection and forest protection with forest fire prevention, forest invasion prevention, etc. (5) Sacrifice / volunteerism, one of the problems for community forest members is the sacrifice, volunteering to take care of the community forest together, applying for the community forest committee. However, most of them think that they are not business because their main mission is farming, farming, earning for their living without time, so they rarely participate in community forest activities, The sacrifice and the volunteer spirit to take care of the community forest is one of the important conditions for the success of community forest management and (6) harmony, It is a cooperation, cooperation, cooperation of all sectors, including community forest committee, community forest members, community leaders, monks, as well as public and private agencies together take care of the community forest, maintain, conserve and rehabilitate the duties of each department, divide the duties and responsibilities, conferences with clear agendas, and create participatory community covenants in conservation, restoration, and maintenance to take advantage of the community forest.

\section{Research Discussion}

This study found some interesting points to discuss the findings as follows.

The management problem in the form of a community forest committee is the division of duties and responsibilities of each party and the regulations that are not clear, many people do not understand their rights and duties, community forest members lack participation. This is because Ban Dong Yang Community Forest is a forest in the responsibility of Moo 8. And Moo 12, with both communities having the right to management and mutual use, but in the official document, only Ban Dong Yang Moo 12 is involved in community forest development in cooperation with the government by law designated, but there is no specify group 8 at all. Many villagers in Village 8 claim that the forests belong to Group 12, thus lacking the motivation to exercise their rights to forest management with Village 12, therefore, these are the issues of sense of Belonging; the feeling that it is not part of the available resources, has led to other problems such as forest 
encroachment, illegal logging, etc. Consistent with the concept of Patamawadee Pochanukul (2005) property ownership is important to the jest, protection, and exploitation, because in economics, a clear proprietary system allows efficient allocation of resources; there is the main characteristics are Exclusivity, Transferability, and Enforceability. When residents lack a sense of true ownership or lack confidence when the state will request the space back, there is a lack of incentive to maintain it. To enable communities to be involved in the stewardship and management of resources, it must first create a sense of ownership and the ability to enforce their rights which same as research of Kingkarn Sumnuanyen, Pissamai Srinate and Orathai Liangjindathaworn (2013) divided the appropriate model for restoration and conservation of Huay Tong Wad with umbrella part of Ban Pho Tak Community, Ubon Ratchathani were At the community level, strengthening and stimulating consciousness, creating a mechanism for management and monitoring, promoting conservation behaviors, including setting up a youth club, and at the policy level must establish a provincial rehabilitation and conservation committee.

Another important issue of the right to utilize Ban Dong Yang community forest resources is the fact that the community does not have an agreement on the amount, time or volume per person to enter the forest, yet is the complete freedom to use the collected forest. In addition, it was found that communities did not understand sustainable forest use, without extending and adding value to community forest products such as planting and expanding vegetation and food from the wild for self-care in their own farmland, reducing dependency on community forests, can allow forests to recover. It may be because community forest directors and members may view it as too far to set such restrictions, but to prevent it is too late to allow community forests to degrade. Natural resources are scarce, when then a deal is reached, it may not be in time. These will reduce dependence on community forests for forest recuperation, preserving and preserving the value of forest resources as well as biodiversity of forest ecosystems in ways appropriate to their livelihoods of people in the community, it is consistent with the research results of Phramaha Prakasit Sirimedho (Thitipasitthikorn), Decha Kuppako and Phramaha Boonlert Inthapanyo (2017) found that communities must have a system of conservation agriculture, which can be indigenous or promoted and have an economy of production, management, self-sufficiency and relationship with forest resources to create Balance the resource base and resource usage patterns without putting too much pressure on forests., and consistent with the study of Patai Wonganutrohd (2001) found that the mutual use resulting from the conservation, protection, restoration, and preservation of community forests is fair share. Everyone in the community is a co-owner, that is, mutual use, respect for rules, rules, rules are the use of people in the community who have common rules, behave in good faith and comply with community rules, as well as respect the rights of the community together.

\section{Suggestions \\ Suggestions for applying the research results}

1.1 Management aspects: Government sector, educational institutions or related agencies should strengthen the management capacity of Community Forests Committee. Should issue rules, regulations, agreements for management and common use. Build partnerships with organizations outside the community in the areas of organizational administration, academic knowledge and forest technology. And fostering awareness of the new generation by creating motivation and a sense of belonging to take part in the care of community forests. 1.2 Utilization aspects: The Community Forest Management Committee should expedite clear regulations on the management, maintenance, and rehabilitation of community forests. Promote learning and create awareness about conservation and restoration of natural resources, environment and biodiversity in community forests, the management of centralized assets of community forests, zoning of protected and functional forest areas that allow their use, must be used sparingly. In addition, fines and penalties for violators of the community should be clearly defined.

\section{Suggestions for further research}

2.1 There should be a comparative study of the community rights issue from many areas with different similarities and limitations to lead to spatial community forest development to drive sustainable community forest development.

2.2 The patterns of natural resource utilization from community forests should be studied for food security and community biodiversity.

\section{References}


Kingkarn Sumnuanyen, Pissamai Srinate and Orathai Liangjindathaworn. (2013). Pattern of conservation and recover of the Huay Tong Wad, Ban Photok, Thambon Pho Yai, Warinchamrap District, Ubonratchathani Province. Bangkok: Thailand Science Research and Innovation (TSRI).

Orrathai Intachaiwong. (2017). "Community Rights in Management, Maintenance, and Utilization of Natural Resources and Environment" Law and Local Society Journal, 1 (1): 171-193.

Patai Wonganutrohd. (2001). SOCIAL NETWORK PROCESSES AND DEVELOPMENT: A CASE STUDY OF BAN NONGKHAO, TAMUENG DISTRICT, KANCHANABURI. Master of Science (Technology of Environmental Planning for Rural Development): Mahidol University.

Patamawadee Pochanukul. (2005). Property Ownership and Environmental Problems. Handouts for the course of Introduction to Natural Resources and Environmental Economics. Academic Service Center for Economics (ERTC), Faculty of Economics: Thammasat University

Phramaha Prakasit Sirimedho (Thitipasitthikorn), Decha Kuppako and Phramaha Boonlert Inthapanyo. (2017). "Scholars of the Forest: The Process of Consciousness Cultivation for the Model Community Forest Management in the Upper Mun River Basin". Journal of MCU Peace Studies, 6 (Special Issue): 61-75.

Pisamai Kongsri. (2019) Members of Ban Dong Yang Community Forest, Interviewed on May 18.

Pitipong Yingpatsaranan. (2019). Former Director of Ban Dong Yang School, Interviewed on May 15.

Rueng Bunjong. (2019). Ban Dong Yang Community Forest Committee, interviewed on May 15.

Ubon Provincial Statistical Office. (2019). Analysis Report of Ubon Ratchathani Province 2015 - 2018. [Online] http://osthailand.nic.go.th/masterplan_area/userfiles /file\%20 Download/report.pdf.

Udomsak Sinthipong. (2015). "Local Community and the Participation in the Management of Natural Resources for Sustainable Use" Executive Journal, 35 (1): 104 - 113.

Wasana Bunprakarn. (2019). Headman of Ban Dong Yang, Village No. 12, Interviewed on May 18. 